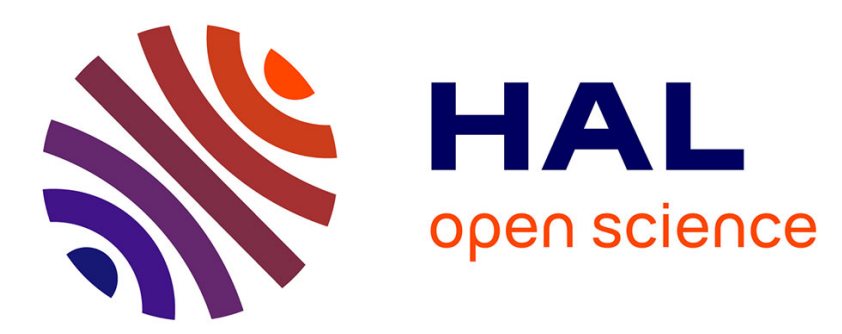

\title{
Turbulence measurements in marine stratocumulus with airborne Doppler radar
}

\author{
M. Lothon, D.H. Lenschow, D. Leon, G. Vali
}

\section{To cite this version:}

M. Lothon, D.H. Lenschow, D. Leon, G. Vali. Turbulence measurements in marine stratocumulus with airborne Doppler radar. Quarterly Journal of the Royal Meteorological Society, 2005, 131, pp.20632080. 10.1256/qj.04.131 . hal-00141972

\section{HAL Id: hal-00141972 \\ https://hal.science/hal-00141972}

Submitted on 15 Mar 2021

HAL is a multi-disciplinary open access archive for the deposit and dissemination of scientific research documents, whether they are published or not. The documents may come from teaching and research institutions in France or abroad, or from public or private research centers.
L'archive ouverte pluridisciplinaire HAL, est destinée au dépôt et à la diffusion de documents scientifiques de niveau recherche, publiés ou non, émanant des établissements d'enseignement et de recherche français ou étrangers, des laboratoires publics ou privés. 


\author{
Turbulence measurements in marine stratocumulus \\ with airborne Doppler radar \\ By M. LOTHON ${ }^{1 *}$, D. H. LENSCHOW ${ }^{1}$, D. LEON ${ }^{2}$ and G. VALI ${ }^{2}$ \\ 1 National Center for Atmospheric Research, Boulder, Colorado \\ ${ }^{2}$ Department of Atmospheric Science, University of Wyoming, Laramie, Wyoming
}

\begin{abstract}
SUMMARY
This study investigates the ability of a W-band radar to measure turbulence structure as a function of height throughout the drizzling marine boundary layer from the fine-structure of the Doppler velocity field obtained during Dynamics and Chemistry of Marine Stratocumulus Experiment using the NCAR C-130 aircraft. In situ air velocity measurements are used as a basis for the comparison with radar measurements of turbulence energy and dissipation, and integral length scale, after correcting for the effects of velocity averaging within the pulse resolution volume and random uncorrelated noise. One essential step for this study is to estimate the contribution to the fluctuations in Doppler velocity due to the terminal velocity of hydrometeors. To do this, we use microphysics probe measurements of the spatial distribution of the drop counts in each size bin. We find a small velocity standard deviation (0.05 to $0.1 \mathrm{~m} \mathrm{~s}^{-1}$ ) contributed by the radar-measured drizzle fall velocity and a substantial negative correlation between air vertical velocity and this fall velocity in the upper part of the cloud. This correlation has an impact on the turbulent energy and dissipation deduced from the Doppler velocity. However, it does not significantly affect the integral scales, which are in good agreement with the in situ measurements. Thus, the radar enables us to obtain the profile of this key variable through the entire cloud-capped boundary layer. We obtain estimates of the dissipation in the lower $2 / 3$ of the boundary layer that are in excellent agreement with the in situ measurements and consistent with the predominant production terms in the turbulent kinetic energy budget.
\end{abstract}

Keywords: Atmospheric boundary layer Remote sensing Cloud physics

\title{
1. INTRODUCTION
}

Turbulence is the means by which properties in the marine boundary layer become vertically well-mixed. Lilly (1968) was the first to give a detailed account of the structure of the marine stratocumulus-topped boundary layer (STBL) and the role that turbulence plays in determining its structure and persistence. The STBL is driven mainly by cloud-top radiative cooling that generates turbulent mixing within the underlying layer. There have been many subsequent studies that describe the main processes in the STBL, particularly the role of turbulence, and point out the climatic importance of this regime (e. g. Stevens et al. 2003b, Lock and Macvean 1999).

Direct measurements of the intensity and scales of turbulence are available from aircraft and from surface-based instruments; both types of measurements consist of time series along lines. When the boundary layer is filled with scatterers, such as cloud and drizzle, Doppler radar measurements can provide more complete two or three-dimensional observations. However some complicating factors arise. The first is that the fall velocities of the hydrometeors are added to the air motions. The second is the relatively large sample volume of the radar. In this paper, we evaluate these factors and demonstrate the use of an airborne Doppler radar for measuring turbulence variables.

The second Dynamics and Chemistry of Marine Stratocumulus (DYCOMSII) field experiment took place off the coast of southern California in July 2001 to study the dynamics and microphysics of marine stratocumulus (Stevens et al.

* Corresponding author: Centre de Recherches Atmosphériques, 8 route de Lannemezan, 65300 Campistrous, France. email address: lotm@aero.obs-mip.fr 
2003a). It combined airborne radar and in situ (i.e. at the instrument location on the aircraft) measurements of dynamical and microphysical variables in this regime. Thus it is well-suited for examining the potential of using radar to obtain turbulence variables in the STBL. During this project, the $95 \mathrm{GHz}$ Doppler Wyoming Cloud Radar (WCR) was mounted on the NCAR C-130 research aircraft with two downward-looking beams and was able to observe the underlying cloudy atmosphere at high resolution. Previously, the radar had been mounted on the Wyoming University King Air aircraft and proved very useful for observing small-scale stratocumulus structure (Vali et al. 1998). Since the Doppler spectral width was not stored during DYCOMS-II, we could not deduce the turbulence dissipation by measuring motions within the sampling volume, as was previously attempted by e.g. Jacoby-Koaly et al. (2002) and Bouniol et al. (2003). Here we investigate the possibility of obtaining turbulence characteristics in stratocumulus using fluctuations of the volume-averaged Doppler velocitiest.

The radar-measured Doppler velocity in the vertical beam $v_{r}$ is a sum of the vertical air velocity $w$ and the droplet fall velocity weighted by reflectivity $v_{t}$. Since the terminal velocity of the scatterers is a monotonic function of droplet diameter, $v_{r}$ depends on the drop size spectrum within the radar volume. Its effect at the turbulent scale has been difficult to obtain and has not been extensively studied. One way to deduce the fluctuations in $v_{r}$ that are due to $v_{t}$ is to assume a power law relationship between average reflectivity and $v_{t}$ (Orr and Kropfli 1999) that can be extended to a relationship between their respective fluctuations (Campistron et al. 1991). However, based on our observations, the assumption of a power-law relationship does not seem valid here. More recently, O'Connor et al. (2004) combined $94 \mathrm{GHz}$ Doppler radar measurements with those from a backscatter lidar to estimate the size, concentration and higher moments of the drop distribution, as well as other microphysical properties of the drizzle below cloud base.

In this paper, we use the in situ drop count measurements with the microphysics probes that were also mounted on the C-130. For the evaluation of turbulence, the droplet spectra would have to be known with a resolution at least equal to the radar sample volume. In drizzle, the sparsity of the larger drops, which contribute significantly to the radar signal, coupled with the limited sample volume of the microphysics probes, precludes direct measurement at that resolution. Hence, a statistical approach is followed: a significant deviation from randomness is observed which we use to estimate the variance in $v_{t}$ from the spatial distribution of drops.

The second issue addressed is the effect of the radar pulse volume averaging on the turbulence variables. Since the Doppler measurements are unequally spaced, we use the autocorrelation function or structure function, rather than the energy density spectrum, to obtain the integral scale and the turbulence dissipation rate. The pulse volume acts as a filter that averages the velocities within the volume defined by the geometry of the beam and the pulse length. Srivastava and Atlas (1974) studied the effect of the volume averaging on a Kolmogorov $-5 / 3$ spectrum. We use a similar method to evaluate its effect on the structure functions, assuming von Kármán spectra for the velocity components.

$\dagger$ We intentionally do not use the usual terminology 'mean Doppler velocity' (Doviak and Zrnic, 1993) because of the possible confusion with the layer averages mentioned later. 

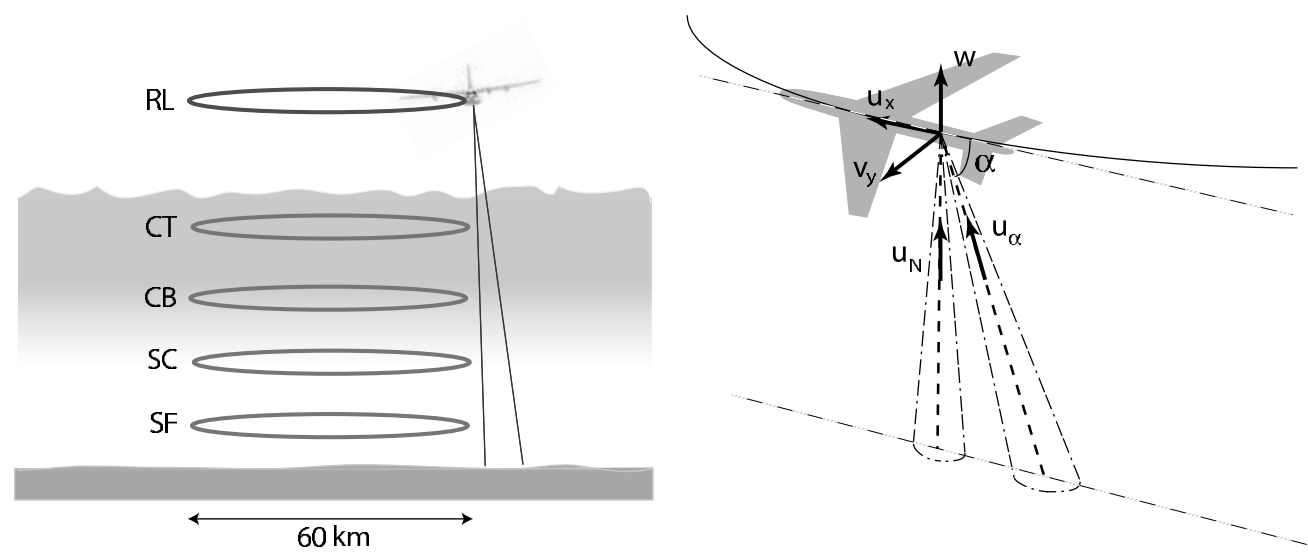

Figure 1. Left panel: Schematic flight plan. Right panel: Schematic view of the aircraft flying a circle leg. The two radar beams are indicated, along with the radar-measured velocity components $u_{N}$ in the vertical and $u_{\alpha}$ at $57.5^{\circ}$ from horizontal, and the components of the wind in the aircraft coordinate system $u_{x}, v_{y}$ and $w$ deduced from the measurements of the navigation and air motion sensing systems.

The next section describes the observational data used in this study. Section 3 deals with the issue of the drop fall velocity contribution. Section 4 discusses the method used to estimate the turbulence characteristics from radar and in situ velocity measurements. Section 5 shows vertical profiles of turbulence variables from DYCOMS-II flight 7, which are discussed further in section 6.

\section{EXPERIMENTAL DATA}

The data used here were collected during flight 7 (RF07) of the seven NCAR C-130 flights that had a similar flight plan during DYCOMS-II and could be considered for this study. This nocturnal flight had the most uniform distribution of drizzle (Van Zanten et al. 2004), which resulted in a radar signal of good quality throughout the entire STBL. Plots of echo coverage (based on a reflectivity threshold of about -20 to $-25 \mathrm{dBZ}$ ) as a function of height for the rest of the flights show that four cases contained nearly $100 \%$ echo at cloud base decreasing to about $40 \%$ echo coverage at $200 \mathrm{~m}$ height. The other two flights had more than $90 \%$ echo coverage at cloud base decreasing to negligible echo at $200 \mathrm{~m}$. It remains to be seen how successfully the techniques described here can be used in cases of less uniform drizzle.

The aircraft flew $60 \mathrm{~km}$ diameter (30 minute) quasi-Lagrangian circles at different levels within the STBL, as well as in the overlying free troposphere, so that the radar could observe the whole STBL (see Fig. 1 left panel). Eight legs were flown within the STBL, two at each of the four levels flown (clockwise and anti-clockwise): near cloud top (CT1 and CT2), just above cloud base (CB1 and $\mathrm{CB} 2$ ), between cloud base and the surface (SC1 and $\mathrm{SC} 2$ ) and $95 \mathrm{~m}$ above the surface (SF1 and SF2). The heights of the legs, as well as cloud base and cloud-top heights are listed in Table 1.

The WCR observed the underlying cloudy atmosphere with two downwardlooking beams. One of the antennas looked straight down and the other backward (57.5 $5^{\circ}$ from horizontal). The radar emitted a $250 \mathrm{~ns}$ pulse with $1.6 \mathrm{~kW}$ peak power and $0.7^{\circ}$ beamwidth. The Doppler velocity was estimated using pulse pair 


\begin{tabular}{cc}
\hline & GPS altitude (m.s.l) \\
\hline Cloud base & 275 \\
Cloud top & 825 \\
RL & 1070 \\
CT1 & 712 \\
CT2 & 677 \\
CB1 and CB2 & 448 \\
SC1 and SC2 & 230 \\
SF1 and SF2 & 95 \\
\hline
\end{tabular}

TABLE 1. Heights of cloud top, cloud base and flight legs flown during DYCOMS-II flight RF07.

processing. Figure 1 (right panel) shows the configuration of the radar and in situ measurements. The in situ wind components in the coordinate system defined by the aircraft heading and the horizontal plane, $u_{x}, v_{y}$ and $w$, were calculated from the navigation and air motion sensing systems at $25 \mathrm{~s}^{-1}$. Profiles of the Doppler velocities, $u_{N}$ and $u_{\alpha}$, along the nadir and the trailing beams respectively, were measured by the WCR at a varying sampling rate of about $20 \mathrm{~s}^{-1}$. Here, we use the fluctuations of $u_{N}$ as an estimate of the fluctuations of $v_{r}$, neglecting the small contribution from variations in the pitch and roll angles.

Only the radar data collected during the circle flown over the cloud top (RL) are considered here. Figure 2 displays the reflectivity and the velocity observed by the nadir radar beam during a 10 kilometer segment that is representative of the entire leg. The in situ data used for comparison with radar measurements and for the microphysics study of section 3 are those collected during the circles flown within the STBL.

To study the spatial distribution of the hydrometeors, we use a FSSP-100 (Forward Scattering Spectrometer Probe) for the small cloud droplets $(2-47 \mu \mathrm{m})$ and a 260X 1D probe $(10-640 \mu \mathrm{m})$ for the larger drizzle drops $(200 \mu \mathrm{m}$ to 500 $\mu \mathrm{m})$. Both probes had a sampling period of $0.1 \mathrm{~s}$.

\section{EFFECT OF HYDROMETEOR FALL VELOCITY ON DOPPLER VELOCITY FLUCTUATIONS}

\section{(a) Issues and approach}

The measured velocity results from an average of the particle velocities within the radar pulse volume, weighted by the hydrometeor reflectivity (Doviak and Zrnic 1993). During RF07, drizzle was prevalent throughout most of the STBL and dominated the observed reflectivity. Cloud droplets, despite being several orders of magnitude more abundant than drizzle drops, contributed insignificantly to reflectivity due to the sixth power reflectivity dependency of the drop diameter.

The variance of a Doppler velocity time series measured with the vertical beam can thus be written:

$$
\sigma_{v_{r}}^{2}=\sigma_{w}^{2}+\sigma_{v_{t}}^{2}+2 \operatorname{cov}\left(w, v_{t}\right)
$$

where $\sigma_{w}^{2}$ and $\sigma_{v_{t}}^{2}$ are the contributions to the total fluctuations of the Doppler velocity due, respectively, to the air vertical velocity and the terminal fallspeed of the scatterers, and cov indicates the covariance term. By convention, $w$ and $v_{t}$ are negative downward. Our goal is to estimate $\sigma_{v_{t}}^{2}$. The covariance term is not quantitatively estimated in this study but is discussed in section 6 . 

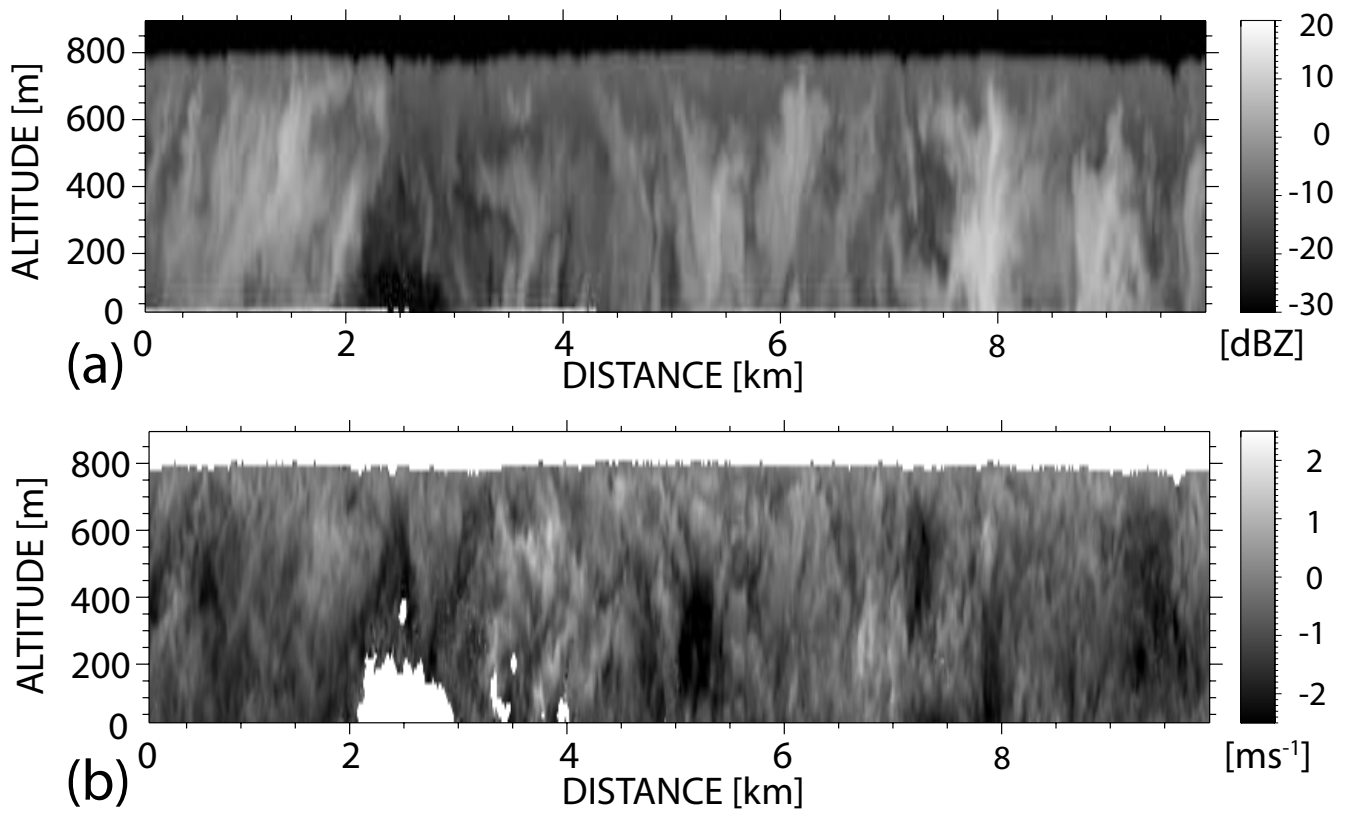

Figure 2. (a) Reflectivity along the nadir beam observed by the WCR during a $10 \mathrm{~km}$ segment of the circle leg of RF07 flown above the stratocumulus cloud. (b) Nadir velocity observed during the same segment. The velocity is negative for downward motion.

The sparsity of the drizzle drops $\left(\sim 0.1 \mathrm{~L}^{-1}\right)$ combined with the small sample volumes of the $260 \mathrm{X}$ probe make it impossible to estimate $\sigma_{v_{t}}$ by straightforward consideration of fluctuations in the drop size spectrum. Rather, a more global viewpoint is necessary. We consider the spatial distribution of the drop counts in each size bin of the probe during the set of two circles flown at each level, and deduce the standard deviation from their departure from homogeneous Poisson statistics. The PMS-observed spatial distribution of drop counts results from a combination of:

1. random counting statistics for a homogeneous distribution, due to the finite number of samples

2. spatial variability in the drop time series, due to physical processes in clouds.

The latter variability produces the observed fluctuations in the Doppler velocity measured by the radar.

If the drop concentration were uniform, with drops randomly distributed in space, a homogeneous Poisson distribution would be expected. However, the concentration varies in space and time. The counting is therefore a generalized Poisson process; i.e. the counting rate varies along the flight path. We assume that the spatial variability is characterized by a lognormal distribution - a hypothesis supported by the radar-observed reflectivity distribution and by previous work (e.g. Hogan and Illingworth 2003, Titov and Kas'yanov 1995). Poisson sampling variations are negligible for the much larger (by 6 orders of magnitude) radar sample volume. The drop counts are accumulated over a sampling interval of $2 \mathrm{~s}$ (about $200 \mathrm{~m}$ long) as a compromise between obtaining a sufficient count rate and resolving turbulence structure. The variations in the in situ-derived 
(a)

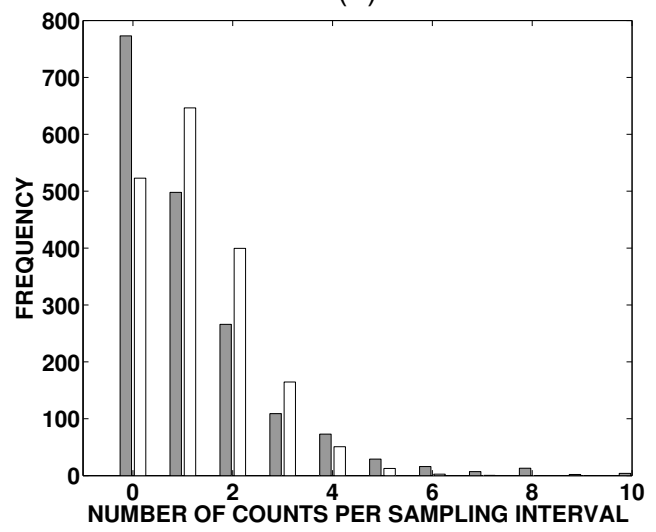

(b)

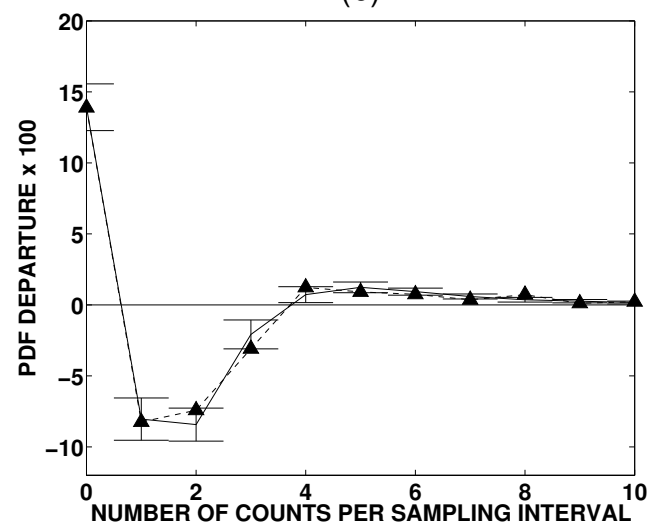

Figure 3. (a) frequency of observed counts per $2 \mathrm{~s}$ sampling time interval for the $115 \mu \mathrm{m}$ channel of the 260X probe for the CB leg (shaded), along with the frequency of counts expected for a Poisson distribution with the same mean number of counts per sampling interval (unshaded). (b) Observed (triangles and dashed line) and modeled (solid line) departure from random Poisson statistics for the $115 \mu \mathrm{m}$ channel at CB leg, using the $\sigma_{n_{i}}$ that best fits the observations. The vertical barred lines represent the standard deviation of 100 cases (100 different artificially-generated random series with the same $\left.\bar{n}_{i}, \sigma_{n_{i}}\right)$.

reflectivity are assumed to be representative of what the radar measures over the same averaging length.

To estimate the standard deviation $\sigma_{n_{i}}$ of the counts in each size bin $i$, we generated a random series for each level based on a Poisson process, but using a lognormally-distributed count rate with $\bar{n}_{i}$ the observed mean number of counts per time interval at a given level and $\sigma_{n_{i}}$ chosen to give a best fit to the observed distribution. This is a more robust procedure than e. g. only fitting the contribution of the lognormal distribution to match the observed variance, and thus obviates to some extent the caution expressed by e. g. Baddeley and Silverman (1984) on using second-order statistics to fit observed distributions. The result is a doubly stochastic process (or Poisson mixture). Figure $3 \mathrm{a}$ shows an example of the distribution of counts per $2 \mathrm{~s}$ period observed for the $115 \mu \mathrm{m}$ channel of the 260X probe during the CB leg, along with the count distribution expected for a homogeneous Poisson process with the same count rate. The measured distribution departs from a Poisson distribution and reveals a clustering very similar to what Kostinski and Jameson (2000) observed at much smaller scales (mm to $\mathrm{m}$ ). Figure 3b shows the observed and modeled departure from Poisson statistics. The error bars on the modeled departure represent the statistical variability over 100 cases. This set of $\left\{\sigma_{n_{i}}, \bar{n}_{i}\right\}$ is used to estimate the standard deviation of the reflectivity-weighted fall velocity (hereafter called the calculated Doppler fall velocity). The mean number of counts per time interval is shown in Fig. 4a for each size bin and leg. As expected, the legs with the most numerous drops are the CB legs, while there are fewer large drops at CT.

We verified that each $\sigma_{n_{i}}^{2}$ added to the Poisson variance $\left(=\bar{n}_{i}\right)$ was equal to the total variance of counts, in order to check that the assumption of two independent processes was valid. The variance calculated directly from a series of counts is the variance due to a Poisson counting process (equal to the mean number of counts) plus the non-Poisson variance contributed by the 
(a)

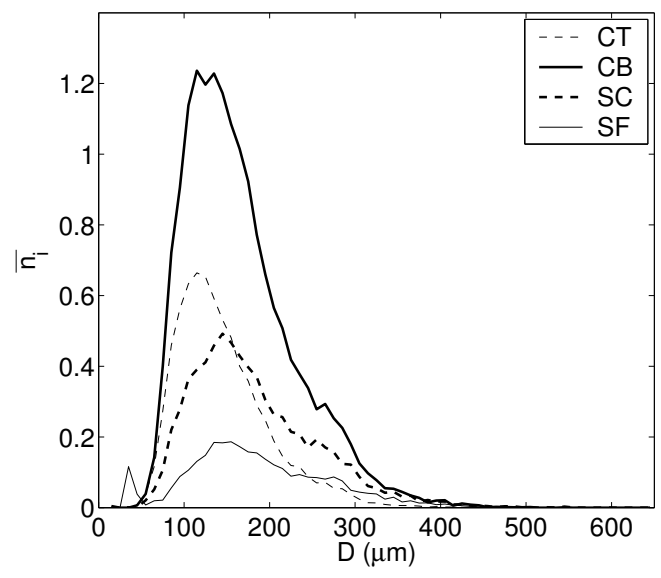

(b)

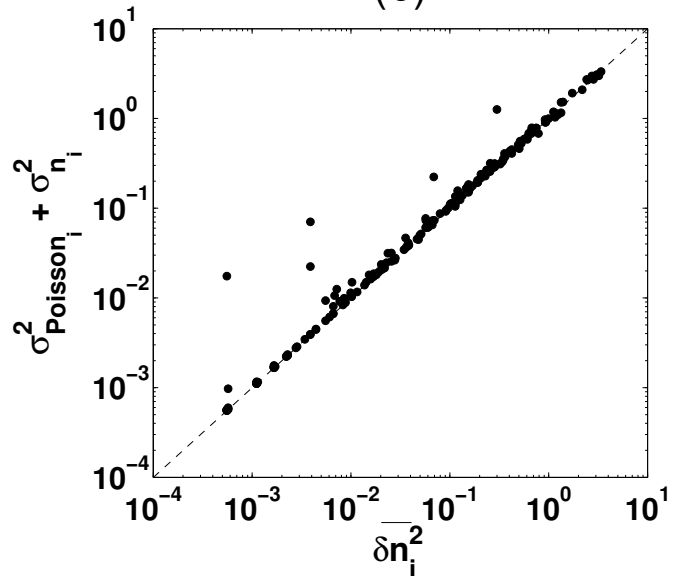

Figure 4. (a) Mean number of counts per $2 \mathrm{~s}$ time interval for each bin size, over the 4 different STBL legs. (b) Sum of the variance in counts calculated from a Poisson random process plus lognormallydistributed cloud heterogeneities versus the total variance obtained directly from the 260X counts. All the legs and size bins are considered here, one point representing one size bin on a given leg. Note the logarithmic scale.

heterogeneities, since the two processes should be independent. Figure $4 \mathrm{~b}$ shows the sum of the Poisson variance $\left(\bar{n}_{i}\right)$ plus the variance due to the lognormal distribution $\left(\sigma_{n_{i}}^{2}\right)$, versus the total variance calculated directly $\left(\overline{\delta n^{2}} i\right)$. The oneto-one slope confirms good agreement between the two estimates of the total variance. This validates our assumption that the two processes are independent and lends further support to our results.

\section{(b) Estimating the drizzle fall velocity contribution to the fluctuations in} Doppler velocity

Another way to check the consistency of the set $\left\{\sigma_{n_{i}}, \bar{n}_{i}\right\}$ is to compare the resulting reflectivity average and variance with the radar measurements from the RL leg. The reflectivity and the calculated Doppler fall velocity of the drops measured by the PMS probe and averaged over the legs are:

$$
\bar{Z}=\sum_{i} \bar{c}_{i} D_{i}^{6} \quad \text { and } \quad \bar{v}_{t}=\frac{\sum_{i} \bar{c}_{i} v_{t_{i}} D_{i}^{6}}{\sum_{i} \bar{c}_{i} D_{i}^{6}} .
$$

The summation is over all the size bins, $D_{i}$ is the diameter of drops in bin $i, v_{t_{i}}$ is the terminal fall velocity of the drops of size $D_{i}, \bar{c}_{i}$ is the average concentration of drops in the same size bin (related to $\bar{n}_{i}$ via the sampling volume) over the two legs flown on the same level. We use the terminal fall velocity as a function of diameter given by Rogers and Yau (1989).

Figure 5a shows a comparison between the in-situ estimated mean reflectivity and the radar mean reflectivity. The probes slightly underestimate the reflectivity because the summation does not take into account droplets smaller than $10 \mu \mathrm{m}$ and drizzle drops larger than $645 \mu \mathrm{m}$. We also note that the STBL legs and RL were separated by somewhere between half an hour and two hours. Despite these differences, the mean profile found with the microphysics measurements is similar to the mean radar measurements (note that the reflectivity scale is not in $\mathrm{dBZ}$ ). 
(a)

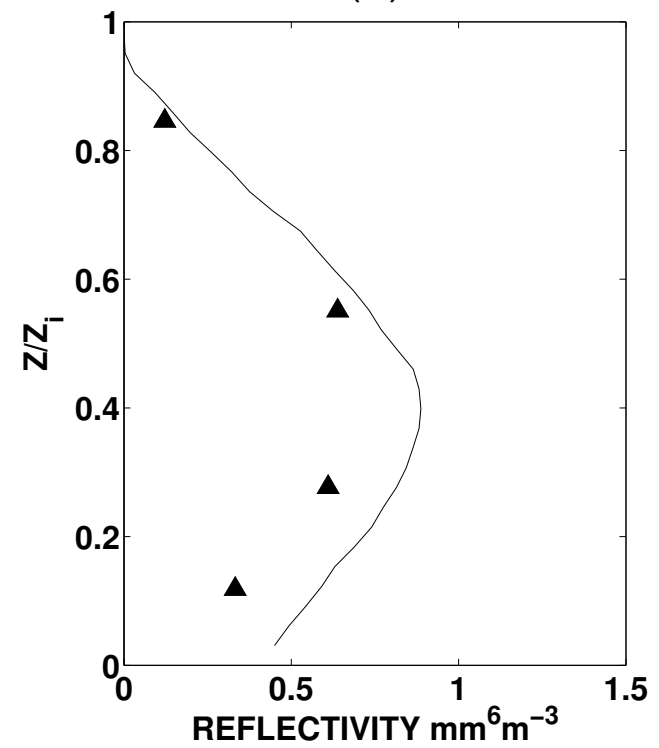

(b)

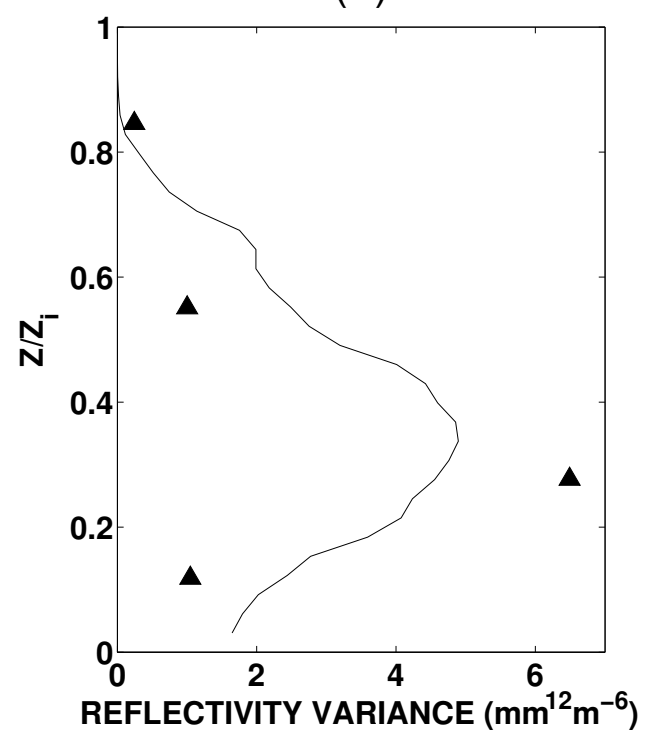

Figure 5. (a) Mean reflectivity profile, with altitude normalized by cloud-top height $z_{i}$ above the surface. Solid line: radar mean reflectivity profile from the radar leg. Closed triangles: PMS measurements. (b) Reflectivity variance profile. Solid line: profile of the radar reflectivity variance over the whole radar leg, obtained from the $2 \mathrm{~s}$ averaged measurements. Closed triangles: reflectivity variance deduced from the PMS measurements, with the assumption that the bin concentration fluctuations are correlated.

We also compute variances of reflectivity and $v_{t}$. For this, we have to make an assumption about the correlation between drop concentrations in different size bins. The following two extreme assumptions are tested: either the size bins are totally independent, or they are completely correlated (the fluctuations are in phase). We find the best comparison between the calculated reflectivity variance and that observed with the radar measurements during the RL leg (Fig. 5b) with the in-phase hypothesis. Therefore, $\sigma_{v_{t}}$ is also calculated using this assumption. We obtain values of $\sim 0.05$ to $0.1 \mathrm{~m} \mathrm{~s}^{-1}$. This is small relative to $\sigma_{v_{r}}$, which is $\sim 0.5 \mathrm{~m} \mathrm{~s}^{-1}$ ) at the same scale.

Since $v_{t}$ is insensitive to any fluctuation in the total number of particles (provided the size distribution function stays the same) the small order-ofmagnitude we find for its standard deviation is consistent with the results of van Zanten et al. (2004) who observed that the normalized drop size distribution (median diameter and width) from 2 minute time intervals hardly changes along the leg, while the total number of particles changes significantly. Because $\sigma_{v_{t}}^{2}$ is about an order-of-magnitude less than $\sigma_{w}^{2}$, this variance will not have a strong impact on $w$ statistics measured with the radar during this flight. However, it is possible that $\sigma_{v_{t}}^{2}$ has been underestimated, since we did not estimate the contribution of scales smaller than $200 \mathrm{~m}$. 


\section{Turbulence analysis method}

\section{(a) Turbulence variables}

The structure and the autocorrelation functions of the wind component fluctuations allow us to describe the fine-scale turbulence (see Monin and Yaglom (1971) for a detailed discussion of structure functions). The second-order structure function is:

$$
D_{i i}(\mathbf{r})=\overline{\left[u_{i}(\mathbf{x}+\mathbf{r})-u_{i}(\mathbf{x})\right]^{2}}
$$

where $\mathbf{x}$ denotes the position vector, $\mathbf{r}$ the displacement vector, and $u_{i}$ is a velocity turbulent component at an arbitrary direction with respect to r. Similarly, the autocorrelation function is:

$$
R_{i i}(\mathbf{r})=\overline{u_{i}(\mathbf{x}) u_{i}(\mathbf{x}+\mathbf{r})}=\sigma_{u_{i}}^{2}-\frac{1}{2} D_{i i}(\mathbf{r}) .
$$

Note that $R_{i i}(0)=\sigma_{u_{i}}^{2}$. These two functions are commonly used to study turbulence variables such as the dissipation of turbulence kinetic energy and integral length scales. An advantage of these functions is that they can be easily computed from time series with missing or unequally-spaced data points and they are directly related to the spectrum $S_{i i}(\mathbf{k})$ via a Fourier transform integrated over wavenumber $\mathbf{k}$ : for the structure function,

$$
D_{i i}(\mathbf{r})=2 \int_{0}^{\infty} S_{i i}(\mathbf{k})(1-\cos (\mathbf{k r})) d \mathbf{k} .
$$

If the turbulence is locally isotropic, then in the inertial subrange (e.g. Monin and Yaglom 1971),

$$
D_{N N} \cong \frac{16}{3} A \epsilon^{2 / 3} r^{2 / 3} \text { and } \quad D_{L L} \cong 4 A \epsilon^{2 / 3} r^{2 / 3},
$$

where $D_{N N}(r)$ and $D_{L L}(r)$ are the transverse and longitudinal structure functions, respectively, $\epsilon$ is the dissipation, and $A$ is the spectral constant for longitudinal turbulence, which we take equal to 0.52 (Fairall and Larsen 1986). We can calculate the transverse structure function $D_{N N}$ using $u_{N}$ measured by the vertical radar beam and the oblique structure function $D_{\alpha \alpha}$ using $u_{\alpha}$ measured by the oblique radar beam, where $\alpha$ is the angle between $\mathbf{r}$ and the direction of the beam. Taking into account the beam geometry and properties of the structure function in the inertial subrange, it can easily be shown that

$$
D_{\alpha \alpha}=\frac{3}{4}\left(1+\frac{1}{3} \sin ^{2} \alpha\right) D_{N N} .
$$

The integral scale of a variable, which is a measure of the length over which a variable is relatively well correlated with itself, is defined as:

$$
L_{i i}=\int_{0}^{\infty} \frac{R_{i i}(r)}{R_{i i}(0)} d r .
$$

A good estimate of the integral scale is obtained from taking the maximum of the running integral of Eq. (8) (Lenschow and Stankov 1986):

$$
L_{i i}(r) \cong\left(\int_{0}^{r} \frac{R_{i i}\left(r_{1}\right)}{R_{i i}(0)} d r_{1}\right)_{\max } .
$$

Thus, estimates of $R_{N N}$ and $R_{\alpha \alpha}$ from the radar measurements can be used to estimate the integral scales $L_{N N}$ and $L_{\alpha \alpha}$. 


\section{(b) Effect of pulse-radar volume averaging}

The radar measurement is not a point measurement but an average within the volume defined by the pulse length and beam width. We examine the effect of this averaging on the turbulence functions. For that, we consider an idealized spectrum and study the effect of the velocity averaging within the radar pulse volume, taking account of the characteristics of the WCR beam and of the measured integral scales. The effect on structure functions is then deduced from the Fourier transform (Eq. (5)) of the filtered spectra, as discussed by Srivastava and Atlas (1974). We assume: (1) Taylor's hypothesis is fulfilled; (2) the reflectivity is uniform inside the radar pulse volume; (3) the beam illumination function within the pulse volume depends only on the distance from the considered point to the center of the volume; (4) the beam width of the radar is small enough to neglect the divergence of the radial velocity within the volume; (5) turbulence is homogeneous and isotropic. Hypotheses (2) and (3) imply that the mean of the Doppler spectrum is an average of the point radial velocities weighted by the mean illumination function; that is

$$
\bar{v}(\mathbf{x})=\int_{V} v\left(\mathbf{x}_{1}\right) I\left(\mathbf{x}-\mathbf{x}_{1}\right) d \mathbf{x}_{1},
$$

where $\mathbf{x}$ is the position of the center of the pulse volume, $\mathbf{x}_{1}$ the position of any point within the volume and the integration is over the radar pulse volume. The Fourier transform of Eq. (10) changes the convolution into a product of spectral density and the beam illumination function (or beam filter function). Considering $k_{1}$ in the beam direction, hypothesis (4) states that the velocity spectral function is equal to $\phi_{11}$. Denoting the beam filter function $\phi_{I}$, the longitudinal and transverse one-dimensional spectra can be written as

$$
\begin{aligned}
S_{L}\left(k_{1}\right) & =\int \phi_{11}(\mathbf{k}) \phi_{I}(\mathbf{k}) d k_{2} d k_{3} \\
S_{N}\left(k_{2}\right) & =\int \phi_{11}(\mathbf{k}) \phi_{I}(\mathbf{k}) d k_{1} d k_{3} .
\end{aligned}
$$

Here, $S_{N}\left(k_{2}\right)$ is the spectrum for the downward-looking beam, orthogonal to the flight direction, while $S_{L}\left(k_{1}\right)$ would be obtained if the radar beam had been pointed parallel to the flight direction (i.e. a forward-looking beam).

The beam filter function, which depends on the characteristics of the beam, is commonly approximated by:

$$
\phi_{I}(k)=\left(\frac{\sin \left(k_{1} c / 2\right)}{\left(k_{1} c / 2\right)}\right)^{2} \cdot \exp ^{\left(-\mu_{2}^{2} k_{2}^{2}\right)} \cdot \exp ^{\left(-\mu_{3}^{2} k_{3}^{2}\right)}
$$

where $c$ is half the pulse length and $\mu_{2} \simeq \mu_{3} \simeq 0.3003 R \theta$ for the WCR, where $R$ is the range and $\theta$ the beamwidth. Equation (13) assumes a Gaussian illumination function transverse to the beam, and a rectangular illumination longitudinally. For homogeneous and isotropic turbulence,

$$
\phi_{11}=\left(1-\frac{k_{1}^{2}}{k^{2}}\right) \frac{E(k)}{4 \pi k^{2}}
$$

where $k^{2}=k_{1}^{2}+k_{2}^{2}+k_{3}^{2}$. We assume a von Kármán energy spectrum,

$$
E(k)=\frac{55}{18} A \epsilon^{2 / 3} \mathcal{L}^{5 / 3} \frac{(\mathcal{L} k)^{4}}{\left(1+(\mathcal{L} k)^{2}\right)^{17 / 6}},
$$


where $\mathcal{L}$ is proportional to the integral scale (Kristensen and Lenschow 1987):

$$
\mathcal{L}=\frac{4 \sqrt{\pi}}{\sqrt{3} \Gamma(2 / 3) \Gamma(5 / 6)} L_{N N} \simeq 2.68 L_{N N},
$$

where $\Gamma$ is the Gamma function. We use the observed integral scale to deduce $\mathcal{L}$. The observed integral scale is of order $100 \mathrm{~m}$ and the characteristic dimension of the radar pulse is $10 \mathrm{~m}$; thus we can assume that the volume averaging has negligible effect on the estimate of the integral scale.

The idealized Doppler longitudinal and transverse spectra are calculated numerically from the von Kármán energy spectrum. The corresponding longitudinal and transverse structure functions - hereafter called modeled structure functions - are then deduced by a Fourier transform of the respective spectra using equation (5).

Here we consider the case of the nadir beam, where the Doppler structure function is transverse. With no volume averaging, the von Kármán one-point double-sided transverse spectrum can be calculated analytically (Mann 1996):

$$
F_{N}\left(k_{2}, \mathbf{x}\right)=\frac{A}{12} \epsilon^{2 / 3} \frac{3 \mathcal{L}(\mathbf{x})^{-2}+8 k_{2}^{2}}{\left(\mathcal{L}(\mathbf{x})^{-2}+k_{2}^{2}\right)^{11 / 6}},
$$

which, when integrated over all $k_{2}$ leads to the variance

$$
\sigma(\mathbf{x})^{2}=\frac{15}{110} \sqrt{\pi} \frac{\Gamma(1 / 3)}{\Gamma(11 / 6)}(\epsilon(\mathbf{x}) \mathcal{L}(\mathbf{x}))^{2 / 3} .
$$

This analytic variance plus a white noise variance added to the volumeeffect-corrected von Kármán structure function are used as parameters to fit the modeled structure functions to the observed at each range. Equation (18) is then used to deduce the dissipation from the variance obtained from the fit.

\section{(c) Application to the data}

In order to obtain the turbulent component of the Doppler velocity from each beam along the circle legs, a preliminary mean analysis was conducted. The geometry of the airborne trajectory allowed us to use a method analogous to the VAD (Velocity Azimuth Display) technique to deduce the mean wind and turbulence components, after correcting for aircraft motion. This method has been named the AVAD (Airborne Velocity Azimuth Display) technique by Leon and Vali (1997). $150 \mathrm{~s}$ segments $(\sim 15 \mathrm{~km})$ of the time series were detrended to obtain the turbulent component.

The in situ air velocity measurements were also partitioned into $150 \mathrm{~s}$ segments for the legs flown within the boundary layer. The circular flight path sinusoidally modulates $u_{x}$ and $v_{y}$. This sinusoidal mean wind signal was removed from each segment to deduce the turbulence components. The in situ vertical velocity $(w)$ was simply detrended over each segment.

$D_{N N}, D_{\alpha \alpha}, R_{N N}$ and $R_{\alpha \alpha}$ were calculated for each 150 s segment with $r$ ranging from 5 to $1000 \mathrm{~m}$, every $5 \mathrm{~m}$, from the Doppler velocity fluctuation measurements along the two down-looking beams. We neglected the change in $v_{r}$ due to the trajectory curvature $\left(\sim 30^{\circ}\right)$ over each segment. For a given range, an average of all 12 structure functions (respectively autocorrelation functions) was used for the mean structure (autocorrelation) function for each 


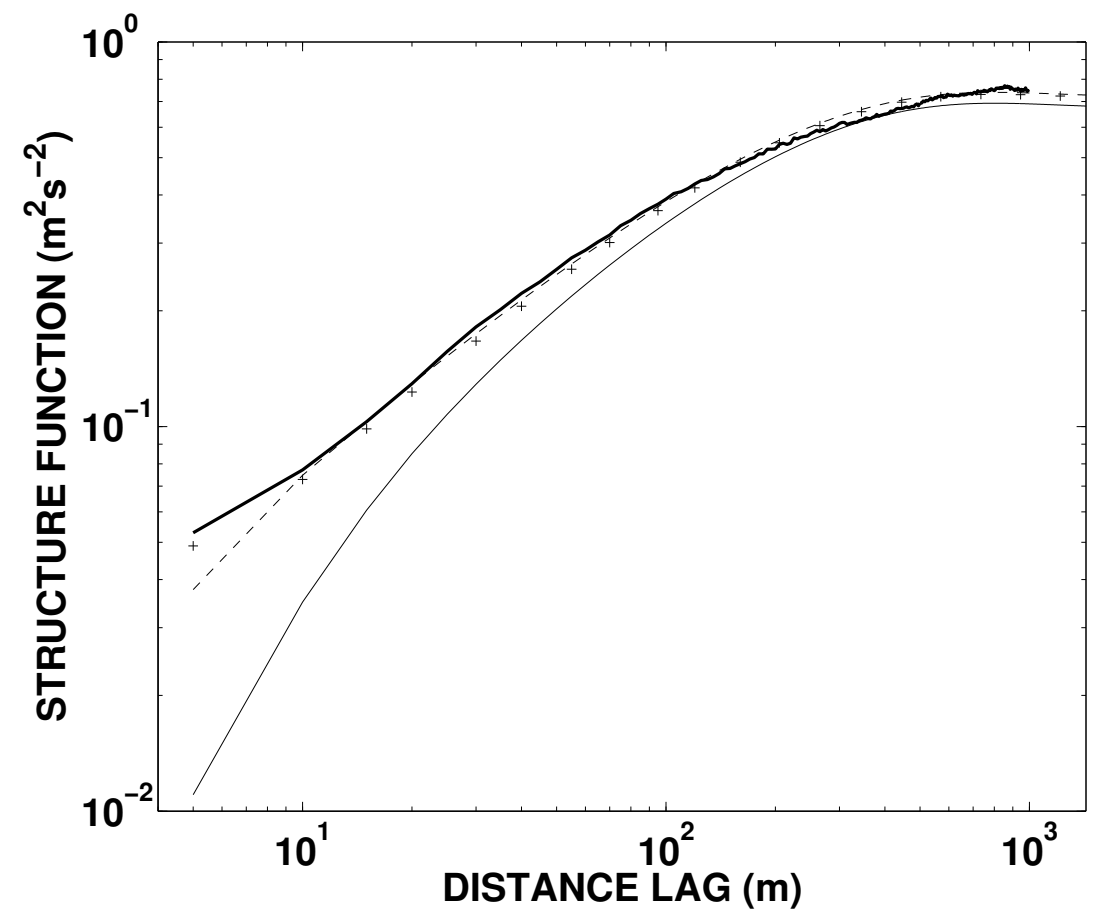

Figure 6. Thick solid line: Observed structure function of the nadir Doppler velocity at $240 \mathrm{~m}$. Dashed line: Corresponding ideal von Kármán structure function. Thin solid line: Structure function after applying the volume averaging to the ideal von Kármán structure function. ' + ' : best fit with the model of a von Kármán energy spectrum, taking account of the volume averaging and including some noise to optimize the fit.

circle. The averaged autocorrelation functions of all range gates were used to obtain the vertical mean profile of the horizontal integral scales for each measured component. The averaged structure functions calculated from the radar Doppler velocity measurements were fit to a modeled structure function described in the previous section, which assumes a von Kármán energy spectrum, using the measured integral scales, and takes into account the radar pulse volume averaging, as well as a white noise contribution. Using a least-squared fitting procedure, we can then obtain estimates of the mean profile of turbulence dissipation.

For comparison with the Doppler velocity turbulence analysis, the autocorrelation functions and spectra of the in situ air velocity measurements made within the STBL were also calculated for each $150 \mathrm{~s}$ segment and averaged over each circle. Integral scales of in situ $w$ and $u_{\alpha}\left(u_{\alpha}=w \cos \alpha+u_{x} \sin \alpha\right)$ were obtained from the autocorrelation functions and turbulent dissipation from the $v_{y}$ spectra, chosen as the most reliable spectra. We used $v_{y}$ rather than $w$ or $u_{x}$ because the inertial subrange slope of $w$ was somewhat steeper than $-5 / 3$ and the $u_{x}$ spectrum appeared noisy at the high wavenumber end of the spectrum.

Figure 6 shows an example of a mean structure function observed at $240 \mathrm{~m}$ altitude with the nadir beam along with the modeled best-fit structure function. The structure function corresponding to the ideal original von Kármán spectrum is also shown, along with the structure function resulting from only the volume averaging. For the example of Fig. 6 , the variance is found to be $0.35 \mathrm{~m}^{2} \mathrm{~s}^{-2}$ and 
(a)

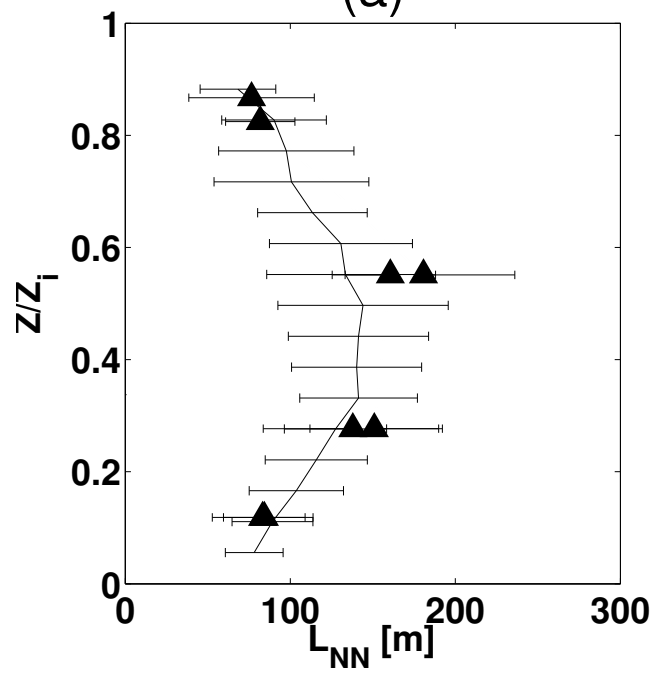

(b)

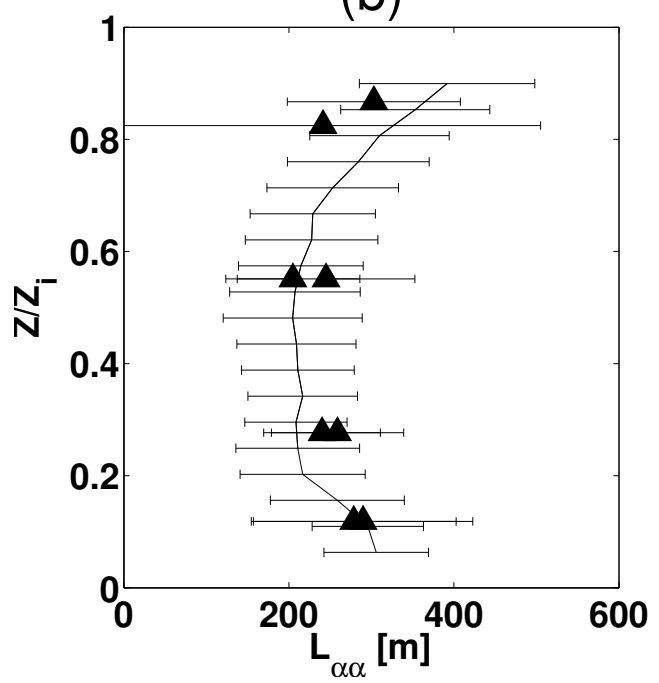

Figure 7. Solid line: mean integral scales in the longitudinal direction for (a) $u_{N}$ and (b) $u_{\alpha}$ measured by the radar beams for flight RF07. The triangles are the mean integral scales of the in situ wind components. The horizontal barred lines are the standard deviations of the integral scale estimates

obtained for each $150 \mathrm{~s}$ segment. Altitude is normalized by cloud-top height $z_{i}$ above the surface.

the noise $0.04 \mathrm{~m}^{2} \mathrm{~s}^{-2}$. The noise generally ranges between 0.03 and $0.1 \mathrm{~m}^{2} \mathrm{~s}^{-2}$, being larger both near the surface and near cloud-top.

\section{Results}

\section{(a) Integral scales}

Figures 7 displays the mean profiles of the integral scales of the Doppler velocities measured on both beams for flight RF07, along with the standard deviations of the set of $150 \mathrm{~s}$ estimates of integral scale. These profiles agree well with the horizontal integral scales calculated with the in situ velocity measurements, which demonstrates that we can obtain this important turbulence length scale from Doppler radar measurements in drizzle. They also show that the pulse volume averaging does not significantly affect the integral scale. We can also see in Fig. 7 the effect of the strong inversion at the top of the boundary layer; the vertical eddies are compressed and thus the vertical integral scale decreases. Similarly, it decreases near the surface. These are characteristics of "squashed" turbulence (Kristensen et al. 1989), which likewise causes the integral length scale for the trailing beam Doppler velocity to increase at the top and at the bottom of the boundary layer due to the broadening of the horizontal eddies as the flow field flattens out close to these interfaces. The difference between the two profiles (a) and (b) of Fig. 7 also demonstrates that the turbulence is increasingly anisotropic near the interfaces.

To obtain estimates of $\sigma_{w}^{2}$ and $\epsilon$, we use only the nadir beam. That is, only the transverse structure function. The observed integral scales shown in Fig. 7a are fit to the modeled structure functions as explained in the previous section. The best estimates are obtained when the radar structure functions are fit only over scales smaller than $50 \mathrm{~m}$. We give an explanation for this in section 6 . 
(a)

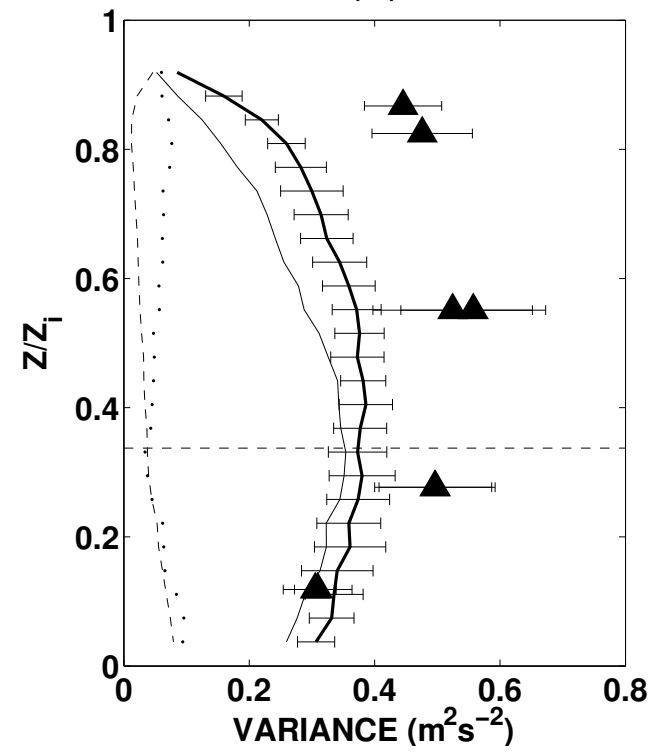

(b)

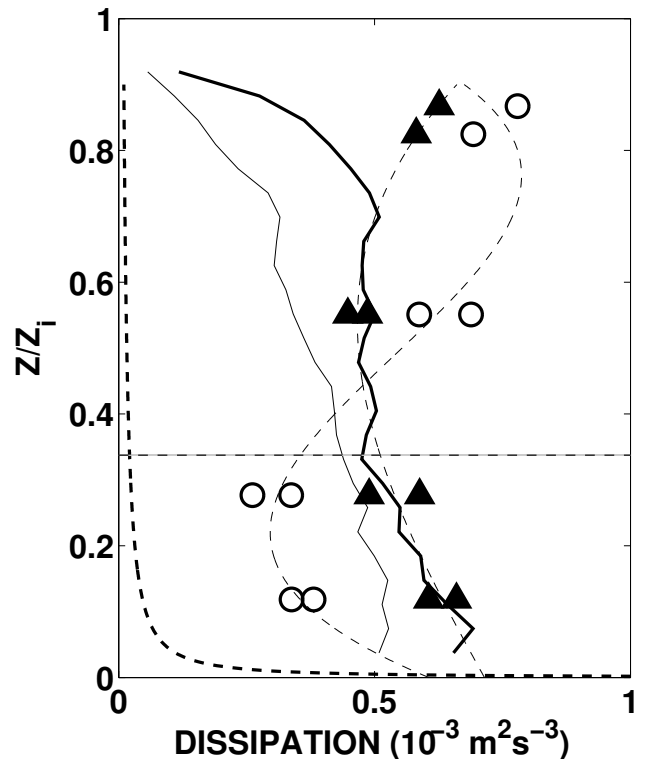

Figure 8. (a) Solid lines: Profiles of $\sigma_{w}^{2}$ found by fitting the observed structure functions of the nadir Doppler velocity to the modeled over wavelengths $<50 \mathrm{~m}$ (thick line) and $<1000 \mathrm{~m}$ (thin line). Dashed and dotted lines are the respective white noise contributions obtained from the fits. (b) Solid lines: Profiles of $\epsilon$ calculated from the nadir velocity measurements over wavelengths $<50 \mathrm{~m}$ (thick line) and $<1000 \mathrm{~m}$ (thin line). The thick dashed line is the shear production and the thin dashed lines are polynomial fits to $\epsilon$ and buoyancy production. In situ measurements of variance and $\epsilon$ are indicated by triangles and buoyancy production by circles. In both (a) and (b), the horizontal dashed line is cloud base.

\section{(b) Turbulent energy}

Figure 8a shows the profiles of both the variance of the vertical velocity measured by the in situ gust probe and the variance of the nadir Doppler velocity during the radar leg, taking account of the noise contribution and volume averaging. Near the surface, the agreement is good, but we observe an increasing departure with height, up to $50 \%$ of the in situ velocity variance in the upper part of the STBL. The volume averaging effect accounts for less than $10 \%$ decrease in variance and is often nearly compensated by the noise contribution which was around $0.05 \mathrm{~m}^{2} \mathrm{~s}^{-2}$. Vali et al. (1998) previously observed in marine stratocumulus that the fluctuations of the Doppler velocity were generally smaller than the actual fluctuations of the air velocity measured in situ, but they did not consider the effects of volume averaging and white noise. Although we do not take account of the dwell time $(\sim 0.04 \mathrm{~s}$ or $4 \mathrm{~m}$ distance), which could make us slightly underestimate the effect of the volume averaging (i.e. make the volume slightly bigger than it actually is), the dwell time is far too short to explain the large departure displayed in Fig. 8a.

\section{(c) Turbulence dissipation}

Figure $8 \mathrm{~b}$ shows the mean profile of the dissipation obtained from both the radar and the in situ measurements. The dissipation estimates from in situ measurements are obtained from a least-squares fit of the $-5 / 3$ power law 
to the mean $v_{y}$ spectrum over each STBL circle within the inertial subrange $\left(0.01<k_{2}<0.5 \mathrm{~m}^{-1}\right)$. The estimates from the radar measurements shown in Fig. 8b are obtained by solving Eq. (18) for $\epsilon$ using the variance found with a least-squares fit of the modeled structure function to the measured function. The agreement is excellent up to about $\frac{2}{3} z_{i}$.

One way to determine the quality of the observed $\epsilon$ values is to compare them to the production terms in the turbulence kinetic energy (TKE) budget. Neglecting horizontal advection and the time rate of change of TKE,

$$
\epsilon=H+S+T_{r}+P_{r}
$$

where $H$ and $S$ are the buoyancy- and shear-generation terms, and $T_{r}$ and $P_{r}$ the divergence terms of the vertical transport of respectively turbulence energy and pressure fluctuations (Lenschow 1974). Integrated over the entire STBL, this expression becomes

$$
\langle\epsilon\rangle=\langle H\rangle+\langle S\rangle
$$

since the transport terms $T_{r}$ and $P_{r}$ do not generate or dissipate kinetic energy. The buoyancy production, defined by

$$
H=\frac{g}{T} \overline{w^{\prime} \theta_{v}^{\prime}},
$$

can be calculated directly from the measurements of vertical velocity and virtual potential temperature fluctuations. The averages found over each circle flown within the STBL are shown in Fig. 8b (circles). The shear production term is more difficult to obtain. We use a simple model suggested by Lenschow (1974) to estimate $S$ throughout the STBL, which assumes that the wind shear in the mixed layer is small and that the variation of the stress with altitude does not affect the shear production significantly. In these circumstances, we can extend the surface layer similarity theory to the entire STBL. Close to the top, however, we expect some discrepancies, since the assumptions are likely not to be true in this region. If we assume that stress is constant with height, $\mathrm{S}$ can be obtained as a function of $z / L$, where $L$ is the Obukhov length, from the relation

$$
S=\frac{g}{T}\left(\overline{w^{\prime} \theta_{v}^{\prime}}\right)_{0} \times\left(-L / z_{i} \frac{\left[1-15\left(z_{i} / L\right) z_{*}\right]^{-1 / 4}}{z_{*}}\right)
$$

where $z_{*}=z / z_{i}$. $\left(\overline{w^{\prime} \theta_{v}^{\prime}}\right)_{0}$ is obtained from a third-order polynomial fit to the measured buoyancy flux profile within the STBL (see Fig. 8b). Taking the von Kármán constant equal to 0.4 , we find $L=-50 \mathrm{~m}$ and the friction velocity $u_{*}=0.23 \mathrm{~ms}^{-1} \cdot u_{*}$ is obtained from $\left({\overline{u^{\prime} w^{\prime}}}^{2}+{\overline{v^{\prime} w^{\prime}}}^{2}\right)^{1 / 4}$ averaged over the circles and extrapolated to the surface (here $u$ and $v$ are the East and North components of the wind). Our estimate of $u_{*}$ is consistent with the bulk aerodynamic stress, $u_{*}^{2}=C_{D}{\overline{U_{10}}}^{2}$, where $\overline{U_{10}}=6.7 \mathrm{~ms}^{-1}$ is the mean wind at $10 \mathrm{~m}$ and $C_{D}=1.2$ $\times 10^{-3}$ (Smith 1989). The profile of the shear-production term obtained from Eq. (22) is shown in Fig. 8b. We also fit the vertical profile of $\epsilon$ with a secondorder polynomial. Given these estimates of the vertical profiles of the dissipation, shear and buoyancy, we integrate them from the bottom of the surface layer to 0.9 $z_{i}$ (above $0.9 z i$, our estimates of all the terms are suspect) and find that the sum of the production terms $\langle H\rangle$ and $\langle S\rangle$ is nearly equal to the dissipation. This lends further credibility to the radar measurements of turbulence dissipation. 


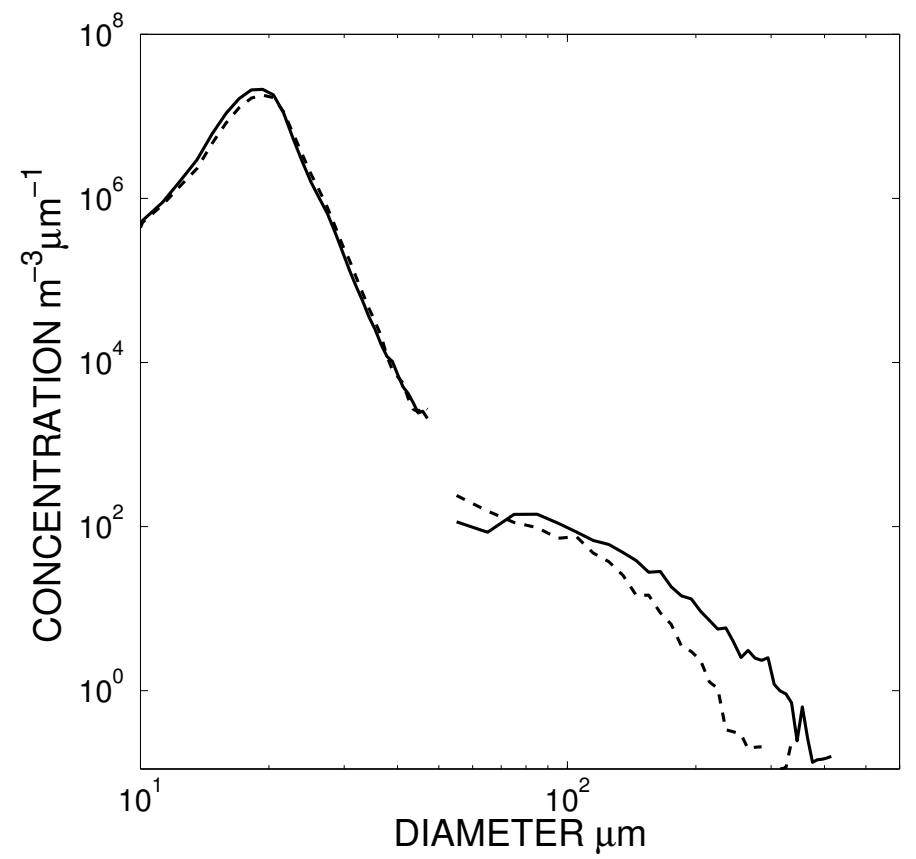

Figure 9. Averaged drop size spectra during CT2 for two size bins conditionally sampled with $w$. The first bin (dashed line) is for $-3 \mathrm{~ms}^{-1} \leq w \leq-0.5 \mathrm{~ms}^{-1}$; the second bin (solid line) is for $0.5 \mathrm{~ms}^{-1} \leq w \leq 3$ $\mathrm{ms}^{-1}$.

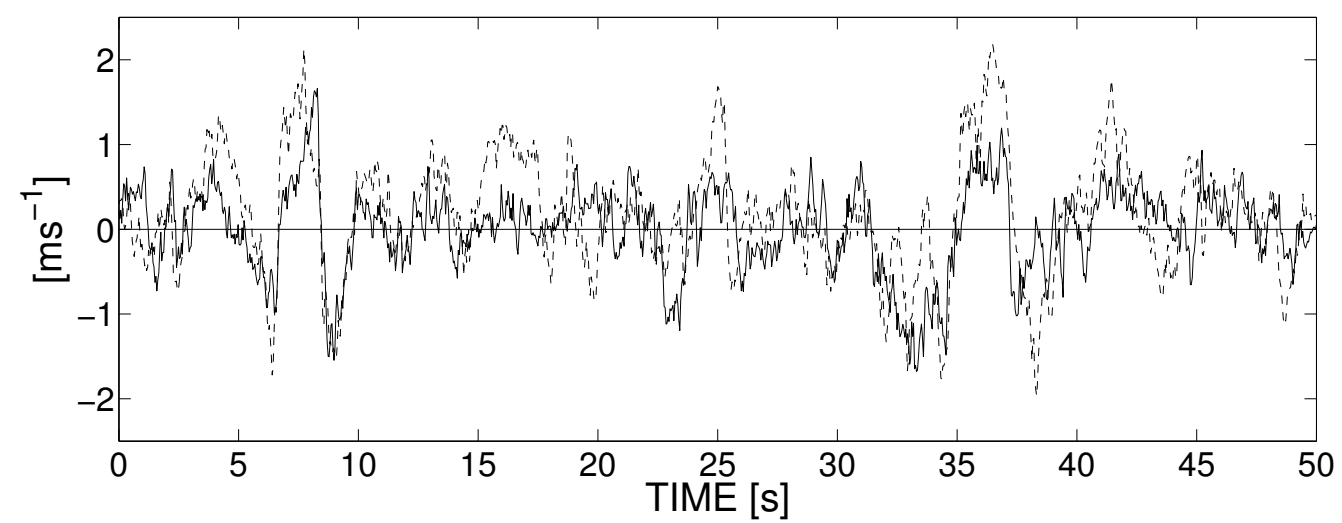

Figure 10. 50 s period time series of the air vertical velocity measured by the in situ gust probe (dashed line) and of the nadir Doppler velocity measured at the third range gate (solid line), near cloud top. Note that the two measurements are $100 \mathrm{~m}$ apart vertically.

\section{Discussion}

The results shown in the previous section - in particular the departure between radar and in situ estimates of velocity variance - are consistent with a significant contribution from the covariance term $2 \operatorname{cov}\left(w, v_{t}\right)$ in Eq. (1). We find evidence of the correlation between air vertical velocity and drizzle drops by conditionally sampling the $10 \mathrm{~s}^{-1}$ FSSP-100 and 260X microphysics probe measurements using the in situ $w$ measurements over the two intervals: -3 
$\mathrm{ms}^{-1} \leq w \leq-0.5 \mathrm{~ms}^{-1}$ and $0.5 \mathrm{~ms}^{-1} \leq w \leq 3 \mathrm{~ms}^{-1}$. The results for CT are shown in Figure 9. There are significantly more drizzle drops compared to cloud droplets in the updrafts than in the downdrafts. The $v_{t}$ difference between the two spectra is about $0.4 \mathrm{~ms}^{-1}$. This feature is also found at cloud base but to a lesser extent, which is consistent with the increasing departure with height that we can see in Fig. 8a. Below cloud base the effect is considerably smaller and is not seen or is even reversed near the surface. This increasing correlation with height between updrafts and drizzle was also observed by Vali et al. (1998). It is consistent with large drops being suspended within updrafts.

In Fig. 10, a 50 second time series of the air vertical velocity measured with the in situ gust probe during CT1 leg and of the Doppler velocities measured at the third range gate during the same leg clearly shows the difference in amplitude of fluctuations in both velocities. It is striking that the updrafts and downdrafts captured by the gust probe are not as strong in the Doppler velocity signal, even though the dimensions of the radar pulse are considerably smaller than the integral scale of the vertical velocity. Figures 9 and 10 demonstrate qualitatively that the link between the drizzle drops and the vertical motion of the air significantly influences the Doppler velocity. However, this correlation is difficult to estimate quantitatively because of the sampling issues involved in measuring the rare large drizzle drops. According to the estimates found for the fluctuations of the Doppler velocity due to the drop fall velocity, this correlation between the vertical velocity of the air and the fall velocity would need to range between 0.8 and 1 to explain such a departure in the upper part of the cloud. Near cloud top, it would need to be unrealistically large. One possible explanation for this is that this correlation has an effect on the structure function itself, and that the observed structure functions cannot be fitted by our modeled structure functions close to the top. The poor fit over all scales between observed and modeled structure functions that we find near cloud top lends support to this hypothesis.

To illustrate this, Fig. 8 also displays (solid thin lines) the energy and dissipation estimates that are found when the radar structure functions are fitted over separations $<1000 \mathrm{~m}$ rather than only over separations $<50 \mathrm{~m}$. The results show that we obtain considerably better agreement with the in situ measurements of dissipation if we consider only the small scales, whereas the variance is only slightly improved by this. This is consistent with the correlation between $w$ and $v_{t}$ affecting the larger scales more significantly, thus affecting the variance estimates more than the dissipation estimates. The departure found at cloud top between radar and in situ estimates of dissipation might be explained by a decrease of the characteristic length scale of the correlation between updrafts and Doppler fall velocity in this region.

A more thorough study of drop count statistics in stratocumulus clouds along with in situ measurements of air vertical velocity might enable us to better estimate both the covariance and variance terms involving the Doppler fall velocity in Eq. (1). One possible way would be to consider the distribution of the time intervals between drop counts, which might allow a higher spatial resolution. However, regardless of how the problem is addressed, the sparsity of drizzle drops along with their large contribution to the radar reflectivity, make this a thorny issue. 


\section{Conclusions}

In order to utilize Doppler velocity measurements to study the characteristics of turbulence in stratocumulus, we use the spatial distribution of drops measured by PMS probes to estimate the effect of the drop fall velocity on the Doppler velocity variance. This indirect approach is motivated by the sparsity of drizzle drops in such clouds. We find that the assumption of a lognormal horizontal distribution of hydrometeors in marine stratocumulus combined with Poissondistributed fluctuations in the observed count rate due to the limited sampling volume give good agreement with the observed count distributions for the 260X probe. We also tried fitting the observed distribution with both Gamma and exponential distributions, but find that the lognormal distribution gives a better fit. We are able to deduce the variance of the calculated Doppler fall velocity from the non-Poisson standard deviation of the counts in each size bin. Its magnitude ( 0.05 to $\left.0.1 \mathrm{~m} \mathrm{~s}^{-1}\right)$ is relatively small compared with the standard deviation of the vertical Doppler velocity $\left(\sim 0.5 \mathrm{~m} \mathrm{~s}^{-1}\right)$.

However, a substantial correlation between air vertical velocity and drizzle prevents us from obtaining quantitatively the turbulent energy and dissipation from the radar measurements throughout the entire STBL. This is an important characteristic of marine stratocumulus. But this correlation does not affect the estimate of the integral scales from the Doppler velocity which were in good agreement with the in situ measurements. Furthermore, we obtain very good estimates of dissipation in the first $2 / 3$ of the STBL and reasonable agreement with in situ variance measurements in the subcloud layer, where there is no evidence for a significant correlation.

This study is limited to one flight. Similar work on other DYCOMS-II flights with minimal drizzle where cloud droplets dominate the in-cloud reflectivity and other similar flights in a STBL should be fruitful and would enable us to determine the universality of these results.

\section{ACKNOWLEDGEMENTS}

Support for the DYCOMS-II project was provided by NSF Grant ATM0097053 and ATM-0094956. The EC-130G Hercules aircraft was operated by NSF/NCAR Research Aviation Facility. NSF and ONR provided major funding for the acquisition, development and research use of the Wyoming Cloud Radar. This work was made possible thanks to MMM, ASP and ATD divisions of NCAR, to the University of Wyoming and to a BFE Lavoisier grant from the Ministry of Foreign Affairs of France provided to the first author during a postdoctoral fellowship. The authors would like to thank A. Shelby Frisch, Pavlos Kollias, L. Jay Miller, Raymond A. Shaw, and Guifu Zhang for fruitful discussions.

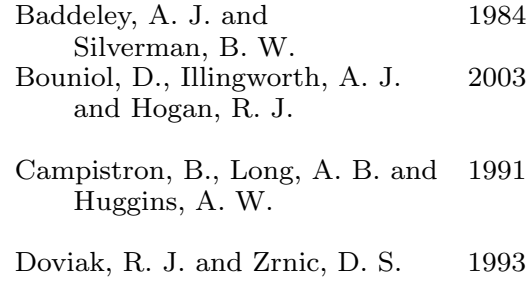

Doviak, R. J. and Zrnic, D. S.

\section{REFERENCES}

1984

2003

(19)

1993
A cautionary example on the use of second-order methods for analyzing point patterns. Biometrics, 40, 1089-1093
Deriving turbulent kinetic energy dissipation rate within clouds using ground based $94 \mathrm{GHz}$ radar. In $31^{\text {st }}$ Confer- ence on Radar Meteorology, Amer. Meteor. Soc. 193-196
A method of retrieving turbulence parameters from volume processing of single-Doppler radar measurements. $J$. Atmos. Oceanic Technol., 8, 491-505
Doppler radar and weather observations. Academic Press


Fairall, C. W. and Larsen, S. E. 1986

Hogan, R. J. and Illingworth, A. J.

Jacoby-Koaly, S., Campistron, B.,

Bernard, S., Bénech, B., Girard-Ardhuin, F. and Dessens, J.

Kostinski, A. B. and Jameson, A. R.

Kristensen, L. and Lenschow, D. H.

Kristensen, L., Lenschow, D. H., Kirkegaard, P. and Courtney, M.

Lenschow, D. H.

Lenschow, D. H. and Stankov, B. B

Leon, D. and Vali, G.

Lilly, D. K.

Lock, A. P. and Macvean, M. K.

Mann, J.

Monin, A. S. and Yaglom, A. M.

O'Connor, E. J., Hogan, R. J. and Illingworth, A. J.

Orr, B. W. and Kropfli, R. A.

Rogers, R. R. and Yau, M. K. Smith, S. D.

Srivastava, R. C. and Atlas, D.

Stevens, B. et al.

Stevens, B., Lenschow, D. H., Faloona, I., Moeng, C.-H., Lilly, D. K., Blomquist, B., Vali, G., Bandy, A.,

Campos, T., Gerber, H., Haimov, S. and Morley, B.

Titov, G. A. and Kas'yanov, Y. I.

Vali, G., Kelly, R., French, J., Haimov, S., Leon, D., McIntosh, R. and Pazmany, A.

van Zanten, M. C., Stevens, B, Vali, G. and

Lenschow, D. H.
Inertial dissipation methods and turbulent fluxes at the airocean interface. Boundary-Layer Meteorol., 34, 287301
2003

2002

2000

1987

1989

1974

1986

1997

1999

1996

1971

2004

1999

1989

1974

2003a

$2003 \mathrm{~b}$

1995

1998

2004
Parameterizing ice cloud inhomogeneity and the overlap of inhomogeneities using cloud radar data. J. Atmos. Sci., 60, 756-767

Turbulent dissipation rate in the boundary layer via uhf wind profiler doppler spectral width measurements. Boundary-Layer Meteorol., 103, 361-389

On the spatial distribution of cloud particles. J. Atmos. Sci., $\mathbf{5 7}, 901-915$

Airborne laser air motion sensing system. II: Design criteria and measurement possibilities. J. Atmos. Oceanic Technol., 4, 128-138

The spectral velocity tensor for homogeneous boundary layer turbulence. Boundary-Layer Meteorol., 47, 149-193

Model of the height variation of the turbulence kinetic energy budget in the unstable planetary boundary layer. $J$. Atmos. Sci., 31, 465-474

Length scales in the convective boundary layer. J. Atmos. Sci., 43, 1198-1209

Retrieval of three-dimensional particle velocity from airborne doppler radar data. J. Atmos. Oceanic Technol., 15, 860-870

Models of cloudy-topped mixed layers under a strong inversion. Q. J. R. Meteorol. Soc., 94, 292-309

The generation of turbulence and entrainment by buoyancy reversal. Q. J. R. Meteorol. Soc., 125, 1017-1038

Personal communication

Statistical fluid mechanics: mechanics of turbulence. John L. Lumley

Retrieving stratocumulus drizzle parameters using Doppler radar and lidar. J. Appl. Meteorol., in press

A method for estimating particle fall velocities from vertically pointing doppler radar. J. Atmos. Oceanic Technol., 16, 29-37

A short course in cloud physics. Butterworth Heinemann

Water vapor flux at the sea surface. Boundary-Layer Meteorol., 47, 277-293

Effect of finite radar pulse volume on turbulence measurements. J. Appl. Meteorol., 13, 472-480

Dynamics and Chemistry of Marine Stratocumulus DYCOMS-II. Bull. Am. Meteorol. Soc., 84, 579-593

On entrainment rates in nocturnal marine stratocumulus. $Q$. J. R. Meteorol. Soc., 129, 3469-3492

Solar radiation fluxes in inhomogeneous stratus. Optika atmosfery $i$ okeana, 8, 1833-1842

Finescale structure and microphysics of coastal stratus. $J$. Atmos. Sci., 55, 3540-3564

On drizzle rates in nocturnal marine stratocumulus. In press in J. Atmos. Sci. 